Don't Forget The Bubbles

\title{
No need to strain: A practical approach to paediatric constipation
}

Ben Lawton, ${ }^{1,2,3}$ Tessa Davis, ${ }^{4}$ Henry Goldstein ${ }^{1,3}$ and Andrew Tagg ${ }^{5,6}$

${ }^{1}$ Emergency Department, Lady Cilento Children's Hospital, Brisbane, Queensland, Australia,

${ }^{2}$ Emergency Department, Logan Hospital, Brisbane, Queensland, Australia, ${ }^{3}$ School of Medicine, The University of Queensland, Brisbane, Queensland, Australia, ${ }^{4}$ Royal London Hospital, London, UK, ${ }^{5}$ Emergency Department, Footscray Hospital, Melbourne, Victoria, Australia, ${ }^{6}$ Adult Retrieval Victoria, Melbourne, Victoria, Australia

\section{Corresponding author:}

Dr Ben Lawton, Emergency Department, Logan Hospital, Armstrong Road and Loganlea Road, Meadowbrook, Logan City, QLD 4131, Australia. Email: ben.lawton@yahoo.com

Ben Lawton, BSc (Hons), MBChB, FRACP (PEM), Paediatric Emergency Physician; Tessa Davis, BSc (Hons), MBChB, MA, MRCPCH, FRACP, Paediatric Emergency Trainee; Henry Goldstein, BPharm (Otago), MBBS (Qld), Paediatric Registrar; Andrew Tagg, BSc (Hons), MBBS, MRCSEd A\&E, FACEM, Emergency Physician.

Difficulty passing stool is a common affliction of childhood with consequences affecting the social and emotional well-being of both child and family. Internationally agreed, evidence based, recommendations exist covering the diagnosis $(1,2)$, investigation $(1,2)$ and management (2) of childhood constipation. Familiarity with these recommendations allows the emergency physician to avoid unnecessary investigation and commence effective management as part of the discharge process, meaning the child's journey to recovery is well underway by the time of their paediatric assessment or follow up in primary care.

\section{Who can't poo?}

The prevalence of paediatric constipation is estimated at $3 \%$ worldwide (3), with rates peaking around the time of toilet training (2-3 years). Fewer than $5 \%$ of these children will be

This is the author manuscript accepted for publication and has undergone full peer review but has not been through the copyediting, typesetting, pagination and proofreading process, which may lead to differences between this version and the Version of Record. Please cite this article as doi: $10.1111 / 1742-6723.12887$

This article is protected by copyright. All rights reserved. 
found to have an underlying organic pathology though this is more common in younger infants, who are dealt with as a separate group in the recommendations (2). More than $95 \%$ of children from 1-4 years of age will pass stool between three times daily and once every other day (4). Younger infants average a higher rate of stool passage but frequency in healthy babies is notoriously variable. The mean rate is three stools per day (4) but anything between seven or even 10 times per day, to once every seven days is widely considered normal in infancy.

\section{What should we do?}

A history and physical examination are all that is required in the vast majority of children presenting with constipation. These should targeting signs and symptoms of other disorders that can present with difficult stooling. Comprehensive differential diagnostic lists are available in table form in the evidence based consensus document produced collaboratively by the European Society for Paediatric Gastroenterology, Hepatology and Nutrition (ESPGHAN) and the North American Society for Pediatric Gastroenterology, Hepatology and Nutrition (NASPGHAN)(2). A careful review of more generic red flags will reassure as to the absence of most of these. This international guidance is clear that laboratory investigations are not recommended in the absence of red flag symptoms (2). The classic history of a child with functional constipation begins with the passage of a hard, painful stool. This leads to a reluctance to pass stool, withholding behaviour and subsequent increase in stool size. This begets a vicious cycle of painful stooling and retention. The rectum becomes distended resulting in overflow faecal incontinence, loss of rectal sensation and, eventually, loss of the normal urge to defecate. Typical symptoms include infrequent (less than twice per week) passage of hard or painful motions which may be large enough to 
block the toilet, retentive posturing and/or passage of stool at inappropriate times or places (1).

Dietary and fluid intake is best evaluated with a three-day diary. Though impractical in the emergency department, discharge advice to complete one of these in preparation for follow up appointments is helpfu. Specific advice regarding increasing fibre, fluid intake, exercise or the use of prebiotics or probiotics have not proven to be helpful (2) but general advice regarding the importance of a balanced diet and regular exercise is reasonable.

Examination should include completion of a growth chart. Systemic symptoms including weight loss warrant further investigation. Stool is often palpable in the left iliac fossa but other abdominal masses should be deliberately sought. Inspect the perianal area for anal position, skin tags or fissures. Perianal bruising or extreme distress in the child when assessing the perineum raises the question of sexual abuse but is not pathognomic. Look for any sacral pits or dimples which may be associated with spina bifida occulta or tethering of the spinal cord. Any abnormalities on neurological examination of the lower limbs warrant further investigation, often in the form of magnetic resonance imaging (MRI). Digital rectal examination is not routinely indicated (2) and may traumatise the child further.

\section{The forum in Raleigh}

The Rome Foundation provides the forum for discussion of functional gastrointestinal disorders across the lifespan, including functional constipation in childhood. The current, fourth, iteration of their diagnostic criteria for this condition (Rome IV)(1) differs from earlier versions in that symptoms need now only be present for one month for diagnosis. They have also altered the statement regarding exclusion of other medical conditions suggesting only that "appropriate medical evaluation" is required. This was a deliberate effort to place the 
emphasis on clinical rather than laboratory or radiological evaluation and acknowledge that functional constipation can co-exist with other gastrointestinal pathology (5).

\section{Where do we start?}

Around $97 \%$ of healthy, term infants will pass meconium in the first 24 hours of life and $99 \%$ within 36 hours(6). With delayed passage of meconium, cystic fibrosis, hypothyroidism. and Hirschprung's disease are prominent concerns. Both cystic fibrosis and hypothyroidism are sought as part of the routine neonatal screen that is taken around day three of life so, while not $100 \%$ sensitive, ensuring its completion is helpful. Classically Hirschprung's disease is also associated with poor feeding and abdominal distension. Up to $90 \%$ of affected infants will fail to pass meconium in the first 24 hours of life (7). Diagnosis is by rectal suction biopsy meaning infants with a history of difficult stooling from birth warrant referral to a paediatric surgical service.

Infant dyschezia is a tightly defined functional disorder including at least 10 minutes of straining and crying before successful or unsuccessful passage of soft stool in an otherwise healthy infant younger than nine months of age. Infant dyschezia does not require treatment and suppositories or digital stimulation should be explicitly avoided.

\section{A picture of poo?}

Abdominal radiographs are not indicated in developmentally typical children without red flags on history or examination. Various scoring systems have been developed in an attempt to diagnose functional constipation radiographically. All perform poorly and ESPGHAN/NASPGHAN recommend against the use of abdominal radiography to diagnose functional constipation (2). Transabdominal rectal ultrasonography has been used to show 
differences in both constipated and non-constipated children (8) and before and after laxative treatment in a constipated cohort (8). This may have a role to play in the diagnosis and particularly assessment of treatment response in the future but is currently not recommended routinely (2).

\section{Softly, softly}

Macrogol 3350 is the single most important tool in managing childhood constipation. Macrogol is the international non-proprietary name for polyethylene glycol (PEG) and studies referring to PEG are talking about the same stuff. Several macrogols are used for various clinical indications with the trailing number referring to the average molecular mass. Macrogol 3350 is the specific form used in the treatment of constipation. Macrogol 3350 is an osmotic laxative that acts as an inert vehicle holding water in the bowel and thereby softening the stool. As it is not absorbed and does not interact with the bowel wall itself neither toxicity nor tolerance are an issue.

Brands commonly encountered in practice in Australia include Movicol, GoLYTELY and Osmolax. While all contain the same active (or inactive) ingredient in the form of Macrogol 3350, Movicol and GoLYTELY also contain balanced electrolytes causing some children to complain of a salty taste. Osmolax does not contain these electrolytes. Preparations with balanced electrolytes are indicated if large doses are to be used (such as for bowel irrigation) but at maintenance doses it matters little in practice.

The safety profile of these medications means that parents should feel comfortable adjusting the medication dose to consistently achieve stools with the firmness of toothpaste, mashed potatoes or soft serve ice-cream. Maintenance treatment with stool softeners should continue for at least two months (and one month beyond the resolution of symptoms) (2) as 
rectal distension leaves treated patients prone to re-accumulating stool. Enemas and suppositories do not achieve anything that Macrogol 3350 alone cannot and their routine use is not recommended (2). Phosphate enemas can lead to dangerous hypocalcaemia and extreme caution should be exercised with their use in children.

Use of a footstool to raise the knees above the hips while seated on the toilet improves the chances of successful passage of stool by straightening the rectum to allow efficient emptying. The gastro-colic reflex can be used to good effect by recommending that children sit on the toilet for five minutes after every meal (excluding lunch if school aged). Sticker charts are a fun and helpful way of rewarding children who comply with such a request. The five minutes of sitting should be rewarded rather than the successful production of stool as the behaviour is within the child's control while the passage of stool may not be.

\section{Conclusion}

A careful history and examination will negate the need for laboratory or radiological investigation in the vast majority of children suffering from this common childhood affliction. Discharge instructions should include the use of Macrogol 3350, appropriate timing and incentivising of toileting as well as use of a foot stool to optimise biomechanical advantage. Follow up in primary care is appropriate for most children and the need for ongoing use of stool softeners should be highlighted. Adherence to evidence based management recommendations in childhood constipation has the potential to significantly reduce distress for patients and families while simultaneously improving emergency department workflow and reducing healthcare costs.

\section{References:}

This article is protected by copyright. All rights reserved. 
1. Hyams JS, Di Lorenzo C, Saps M, Shulman RJ, Staiano A, van Tilburg M. Childhood functional gastrointestinal disorders:Child/adolescent. Gastroenterology 2016;150(5):145668

2. Tabbers MM, Di Lorenzo C, Berger MY, Faure C, Langendam MW, Nurko S, Staiano A, et al. Evaluation and treatment of functional constipation in infants and children: Evidence based recommendations from ESPGHAN and NASPGHAN. Journal of Pediatric Gastroenterology and Nutrition 2014;58(2):258-274.

3. Van den Berg M, Bennings MA, Di Lorenzo C. Epidemiology of childhood constipation: a systematic review. American journal of Gastroenterology 2006;101(10):2401-9

4. Corazziari E, Staiano A, Miele E, Greco L. Bowel frequency and defecatory patterns in children: a prospective nationwide survey. Clinical Gastroenterology and Hepatology 2005;3(11):1101-6.

5. Koppen IJN, Nurko S, Saps M, Di Lorenzo C, Benninga MA. The pediatric RomelV criteria: what's new? Expert review of gastroenterology and hepatology 2017;11(3):193-201

6. Metaj M, Laroia N, Lawrence RA, Ryan RM. Comparison of breast and formula fed normal newborns in time to first stool and urine. Journal of perinatology 2003;23(8):624-8.

7. Kessmann J. Hirschprung's Disease: Diagnosis and management. American Family Physician 2006;74(8):1319-1322

8. Joensson IM, Siggard C, Rittig S, Hagstroem S, Djurhuus JC. Transabdominal ultrasound of the rectum as a diagnostic tool in childhood constipation. Journal of Urology 2008;179(5):1997-2002

This article is protected by copyright. All rights reserved. 


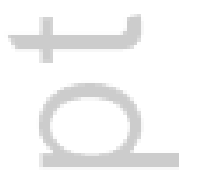




\section{University Library}

\section{- M M I N E R VA A gateway to Melbourne's research publications}

Minerva Access is the Institutional Repository of The University of Melbourne

Author/s:

Lawton, B;Davis, T;Goldstein, H;Tagg, A

Title:

No need to strain: A practical approach to paediatric constipation

Date:

2017-12-01

Citation:

Lawton, B., Davis, T., Goldstein, H. \& Tagg, A. (2017). No need to strain: A practical approach to paediatric constipation. EMERGENCY MEDICINE AUSTRALASIA, 29 (6), pp.616-618. https://doi.org/10.1111/1742-6723.12887.

Persistent Link:

http://hdl.handle.net/11343/293794 